\title{
REDES SOCIAIS INFORMAIS E COMPARTILHAMENTO DE SIGNIFICADOS SOBRE MUDANÇA ORGANIZACIONAL
}

\section{RESUMO}

O objetivo central do presente estudo consistiu em explorar o compartilhamento de significados atribuídos à mudança organizacional no interior de redes informais intra-organizacionais. 0 estudo foi conduzido em um setor de uma empresa petroquímica de grande porte no Pólo Petroquímico de Camaçari (BA), que passara pelo processo de privatização. Foram aplicados questionários a uma amostra de 52 trabalhadores que levantavam as relações de amizade, confiança e informação constituintes das suas redes informais. Itens abertos levantaram cognições sobre o processo de mudança em curso na empresa. As redes foram identificadas utilizando-se os softwares U cinet e $\mathrm{N}$ et Draw, caracterizando-se suas dimensões macro e microestruturais. Os dados sobre as percepções da mudança foram analisados qualitativamente, criando-se categorias descritivas. Os resultados revelam uma visão predominantemente positiva da mudança e níveis reduzidos de densidade e coesão das redes informais. No único clique identificado, observou-se maior compartilhamento do significado atribuído à mudança. Além de mostrar as relações investigadas, o estudo fornece uma estratégia metodológica que pode se revelar heurística para novas pesquisas embasadas em uma perspectiva cognitivista.

\section{Antonio Virgílio B. Bastos \\ UFBA}

\section{Mariana Viana Santos}

UFBA

\begin{abstract}
he present study intends to explore the shared meanings of organizational change inside informal and internal organizational social networks. This study was conducted in a sector of a large scale petrochemical organization in Polo Petroquímico de Camaçari in the Brazilian state of Bahia undergoing a privatization process. Questionnaires were applied on a sample of 52 workers to obtain the relationships of friendship, trust and information making up the informal relationship network. O pen questions allowed obtaining knowledge about the change taking place in the organization. The networks were identified through U cinet and N et Draw software's, and characterized as macro and micro structural dimensions. The data about perceptions were analyzed with a qualitative methodology and descriptive categories were created. The results show a mostly positive vision of the change and low levels of density and cohesion of the informal networks. In the only clique identified, more shared meanings attributed to changes were observed. This study provides a useful methodological strategy that can be very resourceful to new researchers adopting a cognitivist perspective.
\end{abstract}

PALAVRAS-CHAVE Redes informais intra-organizacionais, mudança organizacional, cognição organizacional, relação em rede, análise de rede social.

KEMORDSInformal intra-organizational network, organizational change, organizational cognition, network relation, social network analysis. 


\section{INTRODUÇÃO}

A questão central do presente estudo situa-se na intersecção de três grandes domínios de pesquisa no campo dos estudos organizacionais - cognição social, redes sociais e processos de mudança organizacional. Mais precisamente, buscou-se investigar os significados associados à mudança no interior de redes informais intra-organizacionais. Buscou-se entender, por meio das cognições dos atores, como os processos de mudança são significados nas organizações, o que, certamente, afeta toda a dinâmica desses processos. 0 estudo procura, assim, articular fenômenos que não têm sido estudados de forma articulada - as redes sociais informais que estruturam as relações interpessoais e o significado de mudanças organizacionais para os atores envolvidos no próprio processo.

A extensa literatura sobre mudança organizacional é pródiga em tentativas de sistematizar esse multidimensional conceito. Considerando a complexidade envolvida na definição do fenômeno da mudança organizacional, Wood Jr. (2000, p. 212) argumenta que a mudança pode ser vista como [...] "qualquer transformação de natureza estrutural, estratégica, cultural, tecnológica, humana ou de qualquer outro componente capaz de gerar impacto em partes ou no conjunto da organização". Desse prisma amplo, Huber et all (1995, apudLima e Bressan, 2003, p. 50) consideram que a mudança organizacional relaciona-se às modificações na forma como uma organização funciona, na composição de seus membros e líderes, na forma como ela aloca seus recursos ou ainda modificações na forma que ela assume para a realização de suas tarefas. N essa mesma linha de argumentação, Lima e Bressan (2003, p. 25) oferecem um abrangente conceito de mudança, que envolve tanto alterações planejadas como não planejadas em quaisquer dos componentes organizacionais ( pessoas, trabal ho, estrutura, cultura ou relações com o ambiente) e que podem afetar positiva ou negativamente a sustentabilidade da organização.

A mudança organizacional, portanto, é um fenômeno que pode e deve ser apreendido nos múltiplos níveis em que ocorre. As macroanálises que focam seu ol har na estrutura, no ambiente e nos arranjos institucionais são tão importantes quanto as microanálises que buscam captar a intenção dos atores individuais, seus desejos, al ianças e sentidos compartilhados. Em ambos os níveis, é possível afirmar que a compreensão dos processos organizacionais de mudança pode se beneficiar, fortemente, dos pressupostos e recursos metodológicos que marcam a perspectiva da cognição social.

\section{ABORDAGENS AOS PROCESSOS DE MUDANÇA}

\section{Perspectiva da cognição organizacional}

As abordagens mais recentes sobre mudança organizacional enfatizam o papel da percepção dos atores organizacionais ao reconhecerem que as organizações são ambientes ordenados a partir de interpretações desses mesmos atores. Tais interpretações são produzidas por meio de processos em que a seletividade é a tônica dominante, fazendo com que, partindo das informações apreendidas e sel ecionadas, diferentes significados possam ser atribuídos às mesmas condições externas (Weick, 1987; M achado-da-Silva e Fernandes, 1998; M achado-da-Silva, Fonseca e Fernandes, 1998; Bastos e Santos, 2000; Bastos, 2001). Isso sinal iza que tanto as empresas como os estudiosos da administração estão se dando conta de que, se por um lado é preciso, entre outras coisas, rever e mudar as estratégias, os processos, as estruturas e os sistemas de informação, por outro, nada disso será possível sem uma atenção especial aos processos de construção de significado em que o elemento humano está implicado (Silva e Vergara, 2002).

Ao revisar a literatura brasileira que trata do tema da mudança organizacional, percebe-se que, apesar da grande quantidade de estudos, são raros os trabal hos voltados para investigar a mudança a partir da perspectiva cognitivista. Entre eles, por tratarem a mudança do ponto de vista do significado ou sentido atribuído pelas pessoas à mudança, encontram-se os trabal hos de Machado-daSilva, Fonseca eF ernandes (1998); Gonçalves e Machadoda-Silva (1999); Caldas e Hernandez (2001); e Bastos, Souza e Costa (2004).

Em um ensaio teórico, Machado-da-Silva, Fonseca e Fernandes (1998) adotaram a perspectiva cognitiva e institucional para tratar de mudanças e estratégias nas organizações. Os autores buscaram ultrapassar o esquema da escolha racional como padrão para entender os processos de mudança e enfatizaram a influência de fatores como a cognição e as fontes externas de normalização e de legitimação. Desse modo, a transformação organizacional deve ser vislumbrada, além do pressuposto de escolha e planejamento, à medida que fatores de natureza política, cultural e ambiental, dentre outros, também interferem na sua definição e implementação. Os autores apresentam o modo como a estratégia de mudança tem sido abordada na literatura especializada. A evolução dos estudos sobre o tema a partir da perspectiva cognitivista analisa a mudança na óptica da teoria institucional e propõem um modelo de análise a ser submetido a testes empíricos. 
Em um estudo de natureza empírica, Gonçalves e Machado-da-Silva (1999) pesquisaram a influência das forças e padrões ambientais na visão de mundo dos agentes e as ações organizacionais que configuram mudanças estratégicas. Os autores avaliaram a influência do contexto ambiental, definido com base na abordagem institucional em termos de ambiente técnico e ambiente institucional, na construção dos esquemas interpretativos dos diretores da Companhia Paranaense de Energia. Os resultados da investigação Ihes permitiram afirmar que houve significativa influência da dimensão institucional na reestruturação dos esquemas interpretativos dos dirigentes da empresa. Tal resultado corrobora a necessidade de uma ampliação dos quadros de referências, considerando a função legitimadora do ambiente juntamente com sua função técnica, quer dizer, ambiente tratado como fonte de recursos e restrições.

Caldas e Hernandez (2001) tomam a questão da resistência como foco de análise dentro do conjunto de fenômenos implicados nas mudanças organizacionais. Os autores argumentam que a criação de sentido sobre a mudança interfere nas resistências internas enfrentadas ao implementar mudanças ou inovações. Os autores propõem um novo Modelo de Resistência Individual à Mudança. Esse modelo possui estágios, moderados por fatores individuais e situacionais, e procura representar o processo de percepção individual durante a mudança organizacional, desde a exposição ao estímulo até a adoção de um dado comportamento.

Por fim, nessas e em outras pesquisas voltadas a entender como os indivíduos estruturam as suas concepções sobre a mudança e como tais estruturas cognitivas direcionam a adesão e dinâmica do processo de mudança, é comum se encontrar uma opção metodológica que privilegie o indivíduo como unidade de análise. Não importa sejam os indivíduos trabalhadores ou gestores. No entanto, cada vez mais se compreende que os indivíduos estão inseridos em redes sociais - dentro e fora das organizações. Como conseqüência, essas redes podem constituir unidades de análise potencialmente mais ricas para compreender o posicionamento das pessoas e a dinâmica dos processos coletivos.

\section{REDES SOCIAIS INFORMAIS}

Apesar da variedade de idéias associadas ao conceito de rede, é possível identificar elementos que são comuns ou amplamente partilhados, a exemplo de ligação, laço e integração (Loiola e Moura, 1997; e M inhoto e Martins,
2001). Parte-se, aqui, da noção de que a rede é constituída por interações que visam à comunicação, troca e ajuda mútua, e emerge a partir de interesses compartilhados e de situações vivenciadas ( parentesco, vizinhança, local de trabalho, por exemplo).

É possível identificar, entre os anos 1930 e 1940, duas principais fontes de contribuições nas ciências humanas e sociais que configuraram o campo de estudos sobre redes sociais, como nos afirma Scott (2000): na psicologia, aparecem os trabal hos pioneiros de M oreno, Lewin e Heider; na sociologia/antropologia, encontramos as escolas de Harvard e de Manchester. A base para entendimento de redes sociais está na teoria de Moreno, que trabalhou com sociogramas e matrizes sociais em 1934. Embora tenha orientado sua pesquisa para métodos psicoterapêuticos e clínicos, el e contribuiu significantemente para uma forma de representar as propriedades formais das configurações sociais. Moreno desenvolveu métodos de medição de papéis e anál ise de diagramas e sociogramas de papéis de indivíduos e grupos, do ponto de vista da interação de papéis, do conglomerado de papéis e da predição do comportamento futuro. M apear as estruturas no sociograma permite ao pesquisador visualizar os canais de comunicação, identificar líderes e conexões entre as pessoas. 0 sociograma é um diagrama que representa as forças de atração, repulsão e indiferença que operam nos grupos.

Scott (2000), Cartwright e Harary, em 1956, sintetizaram as idéias dos autores anteriores e foram os pioneiros na aplicação da teoria gráfica (dos grafos). Um grafo é um conjunto de pontos (nodos) ligados por linhas (arcos). Os autores apropriaram-se da idéia de pontos conectados por linhas (sociograma) acrescentando sinais e direção, o que possibilitou a análise do ponto de vista de cada membro do grupo. A teoria dos grafos consiste em um corpo de axiomas matemáticos e fórmulas que descrevem as propriedades dos padrões formados pelas linhas.

As redes sociais constituem um recurso teórico e metodológico especialmente útil para os estudos que tomam as organizações como sistemas de significados construídos nas relações e conexões existentes entre os membros organizacionais. Como bem assinalam Kilduff eTsai (2003), a perspectiva da cognição social aplicada às organizações é compatível com a noção de organização como uma rede de cognições. Adicional mente, os autores consideram que o conceito e metodologias desenvolvidos nos estudos sobre redes sociais podem ser relevantes para abarcar análises micro e macroorganizacionais.

Apesar de historicamente recente, a análise de rede 
social torna-se cada vez mais evidente e relevante enquanto corpo específico de métodos. A partir dos teóricos precursores, muitas pesquisas têm sido realizadas no sentido de desenvolver este campo. Até o final da década de 1970, há uma tendência forte de estudos em comunidades e pequenos grupos (esse uso do conceito de rede permanece até os dias atuais). A partir de então, cresce 0 uso de conceito de rede pelos sociólogos e antropólogos. Em 1969, por exemplo, 0 artigo de Michelll (1969, apud Scott, 2000) marca o desenvolvimento da teoria de redes para estudar fenômenos urbanos complexos. A partir de então, intensificam-se os trabal hos sobre redes no campo dos estudos organizacionais.

É importanteadiantarmos aqui al gumas distinções conceituais importantes. A primeira reporta-se ao nível em quese trabal ha a noção de rede, podendo-se diferenciar as redes interorganizacionais das redes intra-organizacionais. As primeiras têm como unidade a própria organização, destacando-se a idéia de que as organizações precisam umas das outras para sobreviver e a base da relação é a troca de serviços, produtos ou recursos (Podolny, Stuart eHannan, 1996; Carval ho, 2000; Candido e Abreu, 2000; Oliver, 1991; Hasegawa eF urtado, 2001; e Penno, 2002). As redes intra-organizacionais, por seu turno, consistem em sistemas de ligação entre pessoas ou atores sociais, dentro das organizações. Nas redes intra-organizacionais são criadas malhas de múltiplos fios unidos por vínculos que podem inclusive ultrapassar os limites físicos da organização.

A segunda distinção importante se refere a dois tipos básicos de redes intra-organizacionais, denominadas rede formal e informal intra-organizacional. A rede social formal é uma série de ligações ou laços prescritos entre posições sociais formais ou padronizadas (Kuipers, 1999). Em contraposição, as estruturas sociais informais não são explicitadas ou prescritas pelas organizações, e baseiam-se em interações que dependem dos atributos pessoais dos participantes, que fazem escolhas voluntárias.

Quer sejam inter ou intra-organizacionais, formais ou informais, as redes são sempre formadas por atores ligados por diferentes tipos de laços que envolvem trocas ou transações. Assim, esses laços podem ser usados diferentemente por indivíduos em diversas situações. Kuipers (1999) considera que, embora um laço possa ser usado para transferir múltiplos conteúdos, estes são específicos aos contextos no qual são formados e não podem ser usados para transferência indiscriminada de todo tipo de recursos. A autora identifica três tipos de rede informais:
- Rede estratégica de informação: trata-se de uma rede cujo material transacionado compõe-se deinformações sobre o que está acontecendo na organização eque afeta todos os seus membros;

- Rede de amizade: é uma rede baseada na troca de afeto, amizade e social ização; e

- Rede de confiança: é uma rede na qual um ator se permite correr riscos, abrindo mão do controle dos resultados e tornando-se dependente de outro ator, sem a força ou coação da relação contratual, estrutural, legal ou de terceira pessoa.

Os trabal hos que privilegiam a análise das redes informais intra-organizacionais, como Krackhardt e Porter (1986), Kuipers (1999), Cross e Prusak (2002), Kilduf e Tsai (2003), Silva (2003), entre outros, têm em comum a visão de que as redes informais são ferramentas invisíveis e poderosas nas organizações. Muito do trabalho só é feito graças aos contatos informais. Os sistemas informais são importantes, pois, operando nos limites organizacionais, as notícias podem circular complementando os canais formais, e a articulação de entendimentos sobre o "modo como as coisas acontecem" podem ter uma influência significativa no comportamento organizacional.

Como se constata na literatura, apesar do intenso interesse despertado pela questão das mudanças organizacionais, não se encontram estudos que busquem apreendê-las no interior das redes sociais que configuram a organização. Ao se considerar que as mudanças organizacionais impõem problemas imprevistos para as pessoas, que são interpretados e solucionados na dinâmica do interior das redes sociais informais, é possível ampliar a nossa compreensão dos processos de mudança. Assim, a mudança pode ser vista como resultado de numerosas interações entre vários atores que, juntos, formam uma rede pela qual 0 conhecimento e a informação circulam e se transformam muitas vezes, até chegar a um resultado observável.

No presente estudo, objetiva-se investigar o compartilhamento do significado sobre a mudança na rede informal de informação. Busca-se descrever as cognições dos atores a respeito da mudança em processamento na organização e analisa-se o quanto essa percepção é compartilhada entre os atores nas redes informais. Assumese, claramente, que um maior compartilhamento dos significados atribuídos à mudança no interior das redes informais pode ser algo que afeta fortemente o ritmo e os resultados das mudanças pretendidas ou delineadas. Parte-se do pressuposto que as cognições dos atores na rede são centrais para o entendimento dos processos de mudança organizacional. 


\section{METODOLOGIA}

Coerente com a metodologia de anál ise de redes sociais, este estudo delimita, como unidade de análise, um setor específico de uma organização, que constitui o caso analisado pela pesquisa. A análise dos significados associados às mudanças, apoiada num referencial cognitivista, levou a se privilegiar uma abordagem qualitativa. As estratégias de mapas cognitivos e de redes sociais utilizadas podem ser inseridas no grupo de pesquisas qual itativas e intensivas, apesar de permitirem trabal har indicadores quantitativos a partir do material qualitativo coletado.

É relatado aqui o caso particular da rede de informação, uma vez que a consideramos mais importante para explorar a construção do compartilhamento de significados sobre a mudança organizacional. Adicional mente, é nas ligações encontradas nesse tipo de rede que circulam temas relacionados ao trabalho. Quer dizer, o conteúdo que circula na rede de informação pode referir-se a aspectos técnicos, processos de trabal ho ou percepções do ambiente, el ementos intrinsecamente associados ao processo de mudança analisado.

\section{Participantes}

0 estudo foi conduzido em uma grande empresa petroquímica da Bahia, mais especificamente no setor de manutenção, e a amostra atingiu 52 trabal hadores (aproximadamente $10 \%$ das pessoas lotadas no setor). A amostra final foi afetada pela disponibilidade dos trabalhadores. De início, os participantes foram sorteados, e os que não puderam responder foram substituídos também por sorteio.

A composição da amostra inclui atores de três microcontextos com características diferentes: a) o subgru po do "núcleo" (terminologia usada pela organização), composto pelos líderes ou gerentes estratégicos e pessoas diretamente ligadas a estes que têm acesso às informações privilegiadas ( secretárias) ; b) o subgrupo de "terceirizados", originado de aproximadamente dez empresas diferentes que prestam serviços para a organização estudada; e, c) o subgrupo de "funcionários", composto por participantes que representam as áreas específicas desse setor da organização petroquímica (técnicos, engenheiros e outros profissionais). A coleta de dados ocorreu por contatos pessoais com gestores da organização, acesso sempre condicionado à autorização da empresa.

\section{Instrumento de coleta de dados}

0 questionário aplicado continha 32 perguntas, distribuídas em três partes: na primeira, foram feitas perguntas so- brea rede de informação. Seguindo o modelo utilizado por Kuipers (1999) e Silva (2003), solicitou-se que o participante citasse, no máximo, 15 pessoas com as quais busca informações sobre o que acontece na empresa. Junto com essa pergunta se apresentava um quadro em que o participante era solicitado a informar a intensi dade da relação, a freqüência de contato, entre outras informações.

$\mathrm{Na}$ segunda parte, buscou-se captar a mudança identificada pelos participantes como a mais importante e solicitou-se que escrevessem como a perceberam. Para isso, eles deveriam descrever idéias, palavras e frases (no máximo 15 evocações) associadas à referida mudança. $A$ terceira parte solicitava dados demográficos e funcionais dos participantes. A pesar de auto-aplicável, estagiárias previamente treinadas estavam presentes no local de trabalho, durante a aplicação, com esclarecimentos do termo de consentimento e garantindo o caráter confidencial das informações.

\section{Procedimento de análise dos dados}

Para analisar o significado da mudança, as evocações (idéias, palavras e frases) coletadas sobre a mudança considerada mais importante em curso na empresa foram agrupadas em 23 categorias pós-estabelecidas, utilizandose procedimentos clássicos de análise de conteúdo, com as categorias emergindo a partir de similaridades, congruências e diversidades encontradas nas idéias expressas em cada evocação.

A freqüência com que cada categoria apareceu no grupo foi apresentada de forma gráfica, com um mapa cognitivo construído com o programa M indmanager versão X5. Cada evocação foi, também, categorizada em sua dimensão avaliativa - positiva, neutra e negativa. A partir da categorização das evocações, examinou-se o conjunto de evocações de cada sujeito, que foi incluído em uma categoria a partir do tipo de evocação predominante. $\mathrm{Ou}$ seja, a percepção do participante foi considerada positiva se o número de evocações com essa característica foi superior ao de evocações negativas e neutras.

A análise de redes sociais de trabalho envolveu o mapeamento e mensuração das relações entre pessoas. Os pontos nodais são as pessoas, e os traços mostram as relações entre as pessoas, fornecendo uma análise visual e matemática de sistemas humanos complexos. Para a análise da rede foi necessária a codificação dos nomes com três letras, terminação em " $\mathrm{f}$ " para Funcionário, "t" para Terceirizado, " $\mathrm{n}$ " para Núcleo, "e" para Funcionário da empresa que não respondeu ao questionário mas foi citado por mais de um ator, e "d" para Funcionário da empresa que não respondeu ao questionário mas foi ci- 
tado por mais de um ator e tem papel gerencial ou de diretoria. Utilizou-se o software U cinet para Windows 6.0 versão 1.00 (Borgatti, Everett e Freeman, 2002) para montar a matriz e confeccionar o mapa gráfico da rede, exportando a matriz para o Programa N etDraw. As redes foram analisadas em sua forma bruta, não simetrizada (que considera todos os nomes citados), e na sua forma validada ou simétrica (só considerando as relações recíprocas).

Os dados coletados sobre a rede permitiram análises macroestruturais (tamanho ou número de pessoas na rede; densidade, medida a partir das relações efetivas e potenciais; e coesão, medida por meio das relações recíprocas) e microestruturais (atores críticos e atores do dique). Foram identificados os seguintes atores críticos da rede de informação:

- Conector central: éo ator que liga a maior parte das pessoas de uma rede informal umas com as outras (Cross \& Prusak, 2002). 0 envolvimento nas relações o torna mais visível para os outros, podendo ser encontrado na rede por estar recebendo ou enviando muitas ligações (Wasserman e Faust, 1998); e

- Expansor de fronteiras: é o ator que conecta uma rede com outras partes ou subgrupos entre si. Ele serve de ol hos e ouvidos do grupo para o mundo externo e tem importante papel no fluxo de informações (Cross \& Prusak, 2002).

Além dos atores críticos, buscou-se identificar possíveis diquesna redeanal isada. Os diques são subgrupos coesos com, no mínimo, três egos que fizeram escolhas recíprocas dentro das redes, nos quais se pressupõe laços fortes, diretos, intensos e freqüentes e, conseqüentemente, homogeneidade de atitudes e comportamentos. Esperava-se, assim, avaliar se em tais subgrupos coesos seria encontrado um maior compartilhamento de significados atribuídos à mudança.

\section{RESULTADOS E DISCUSSÃO}

Entre os participantes, o processo de privatização, ainda recente na empresa, foi considerado a mudança mais importante. Embora a maioria das respostas indicasse claramente a palavra privatização, em muitos casos os participantes reportavam mudanças na estrutura da empresa ou redesenho organizacional e na cultura, mudanças essas claramente decorrentes da alteração de controle acionário majoritário do setor público para um importante grupo empresarial brasileiro.
0 mapa cognitivo constante da Figura 1 apresenta a freqüência das categorias construídas a partir dos conteúdos evocados, quando os participantes pensam sobre essa mudança em processamento na empresa. Apenas para efeito de organização, as 23 categorias estão agrupadas, de acordo com a freqüência de evocação, em quatro níveis: acima de 20 (idéias muito fortes), entre 15 e 20 (idéias fortes), entre 10 e 15 (idéias fracas) e abaixo de 10 ocorrências (idéias muito fracas). Considera-se, aqui, que quanto maior a freqüência de evocação, mais fortes ou significativas são aquelas idéias para o grupo de respondentes.

Examinando-se o conjunto de categorias descritivas, percebe-se que a mudança ocorrida é vista como afetando a carreira e a possibilidade de crescimento profissional e pessoal. Ela é vista como algo que tem reflexo direto na profissional ização, no aumento do conhecimento técnico e na ampliação da exigência de qual ificação. A parecem com bastante força palavras como aprendizagem, crescimento, desenvolvimento ou atualização, que indicam uma percepção de que a mudança está impondo desafios importantes que implicam requal ificações do pessoal.

Essas idéias aparecem associadas a outras que destacam a busca de melhoria dos resultados empresariais, a melhoria dos processos administrativos, o que envolve mudanças nas relações entre chefias e empregados. As muitas idéias claramente positivas, no entanto, convivem com idéias de conteúdo avaliativo negativo, queassinalam tensões, inseguranças e incertezas geradas pela mudança. Tal constatação aproxima-se muito do que vêm apontando os estudos sobre os impactos das mudanças (Bastos, Souza e Costa, 2004; Silva e Vergara, 2002).

Quando se comparam os três subgrupos de participantes, observa-se que o subgrupo do núcleo evocou, principalmente, conteúdos relacionados à gestão administrativa, crescimento profissional, resultados empresariais e relação chefia-empregado. Esses resultados reforçam a conclusão encontrada por Bastos, Souza e Costa (2004), que estudaram as cognições dos gestores sobre mudança em empresas gaúchas. De forma congruente, em ambos os estudos, os gestores evocam as transformações ocorridas no modelo geral de gestão e nas políticas relativas às pessoas, e têm dessas mudanças avaliações mais positivas.

Para os funcionários, além das idéias muito fortes comuns a toda a amostra, foram freqüentes as idéias de incerteza e insegurança, expectativa de mel horias, remuneração (tanto no que se refere a aumento como a diminuição) e relação interpessoal. Embora as aval iações negativas se relacionem à incerteza que a mudança acarreta nos funcionários, verifica-se que há uma abertura para o reco- 
nhecimento de melhorias, de mudanças administrativas e de modelos de gestão de pessoas. Para entender esses resultados é preciso considerar que cabe aos funcionários o papel de operacionalizar as mudanças planejadas pelos gestores, eque são el es que sofrem as conseqüências mais diretas ou o impacto das alterações. Possivel mente, esse fator ajuda a explicar a evidência de uma visão mais crítica por meio das aval iações negativas.

Entre os terceirizados, surgiram conteúdos relacionados à segurança, saúde e qualidade de vida e meio ambiente, possivelmente devido à implantação de programas específicos destinados a esse subgrupo, no sentido de mudar a mentalidade ou al terar a visão a longo prazo de terceirizadas no setor petroquímico. Ressalta-se que, assim como aos funcionários, cabe aos tercei rizados a operacional ização das mudanças planejadas pelos gestores, sendo que a condição de terceirizado o torna ainda mais distante das instâncias decisórias. Ou seja, chegam até esses empregados apenas informações parciais, já que a contratante controla todas as operações da contratada.

As diferenças observadas no peso das diferentes categorias de conteú dos evocad os pel os trabal hadores fortalecem o entendimento de que as cognições organizacionais, neste caso em particular sobre as mudanças em curso na empresa, são filtradas pela condição de inserção do trabalhador na organização. Ou seja, o princípio básico que fundamenta a perspectiva cognitivista no campo dos estudos organizacionais (Bastos, Souza e Costa, 2004 e M achado-da-Silva, Fonseca e Fernandes, 1998) torna-se evidente na presente investigação - os significados atribuídos pel os atores organizacionais a qual quer evento envolvem uma construção pessoal que é afetada pela forma como o indivíduo se insere na organização.

Como assinalado anteriormente, para responder à questão central deste estudo, referente ao compartilhamento de significado sobre a mudança, trabalhou-se apenas com a rede informal de informação, cuja representação gráfica pode ser visualizada na Figura 2, no seu formato não simetrizado (incluindo todas as ligações apontadas pelos atores).

A rede é integrada pelos 52 atores originais, que acrescentaram 42 sujeitos novos (por citação), formando um total de 94 atores. Isso indica a possibilidade de 8.742 relações potenciais [ ( $94 \times 94)$ - 94]. Verificou-se, assim, que a densidade da rede, de 0,0190 , é baixa, significando que apenas $1,90 \%$ do potencial das relações está sendo utilizado. É baixa, também, a coesão, verificada pela existência de um único dique que une os atores ahf-baf-jkf.

Figura 1 - Mapa cognitivo da mudança organizacional.

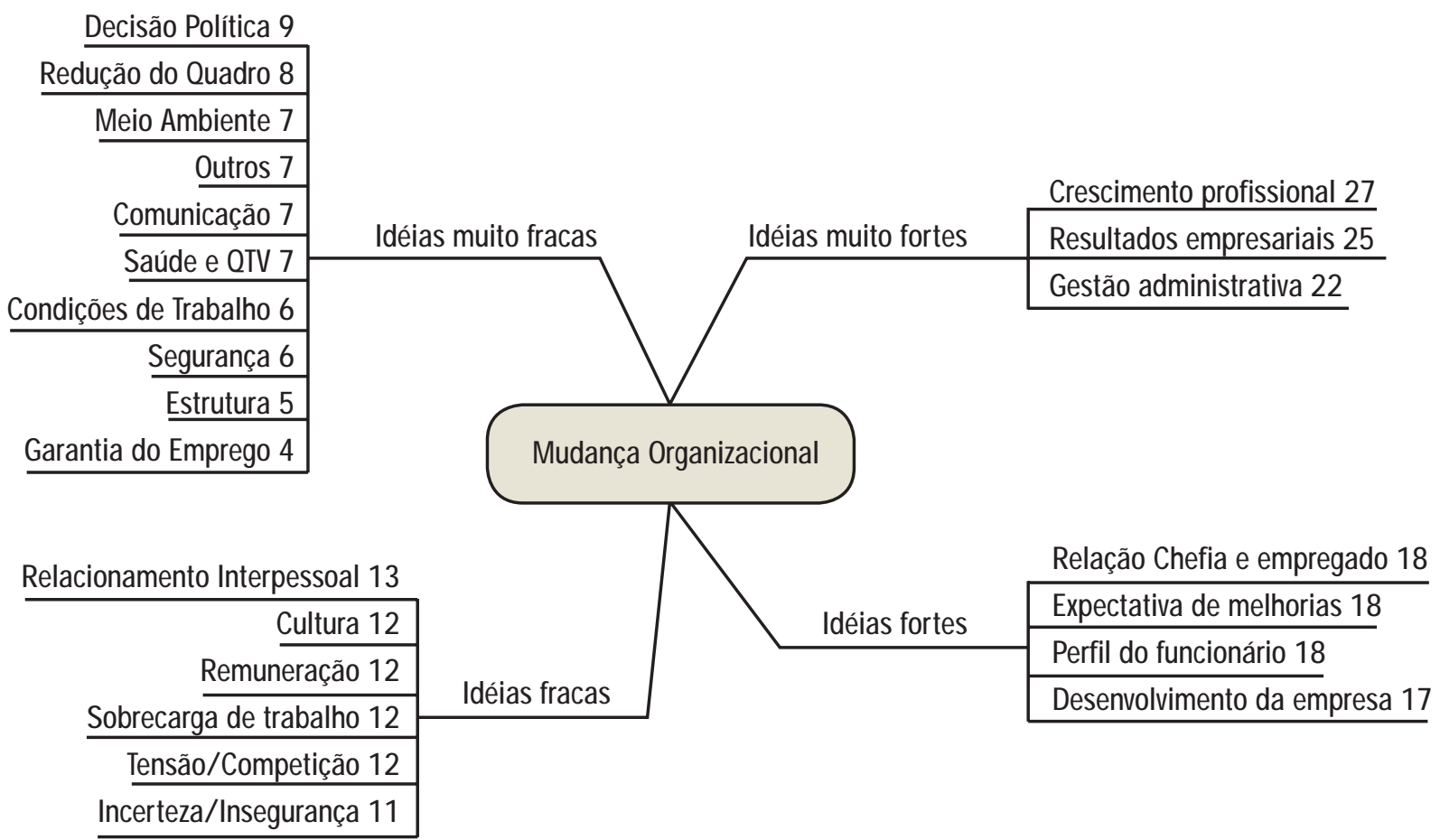


É interessante destacar al go que facilmente se percebe na representação gráfica da rede - o papel periférico das sub-redes que ligam os funcionários terceirizados. Estes ficam na periferia da rede, e, para al guns dos participantes (gtt, jct, ant, ait, por exemplo), não existe conexão com os funcionários ou gestores do núcleo.

A baixa densidade e a baixa coesão da rede de informação ficam ainda mais evidentes na rede de informação simetrizada, constante da Figura 3. Apesar de poucos contatos entre os subgrupos (observa-se apenas uma ligação entre o núcleo e o grupo dos funcionários, formada por jrn-atf), há ligações fortes dentro dos subgrupos percebidas por meio da díade de terceirizados ( hatt-gpt), da tríade do núcleo (jxn-chn-len) e da ligação entre quatro funcionários ( fcf-sdf-eif-rlf).

Finalmente, para articular os dois fenômenos do estu- do, os conteúdos evocados livremente sobre a mudança foram agrupados em três categorias aval iativas (negativo, positivo e neutro) e representados com cores diferentes na rede de informação a partir das relações dos atores críticos, conforme se observa na Figura 4.

As idéias negativas sobre a mudança ou associadas à piora das condições gerais foram agrupadas, e seu conteúdo éconstituído por: condições de trabal ho insatisfatórias, competição entre pessoas, ansiedade, desligamento. A categoria associada a uma avaliação positiva ou que exprime qualidade ou mel horia é constituída por: desenvolvimento da empresa e crescimento profissional. Por fim, a categoria neutra, caracterizada pela ausência de associação direta negativa ou positiva, agrupa idéias tais como: pessoas, distribuição do tempo e reuniões. Os atores que se classificam como conectores centrais são: jrn (neutro),

Figura 2 - Rede de informação não simetrizada.

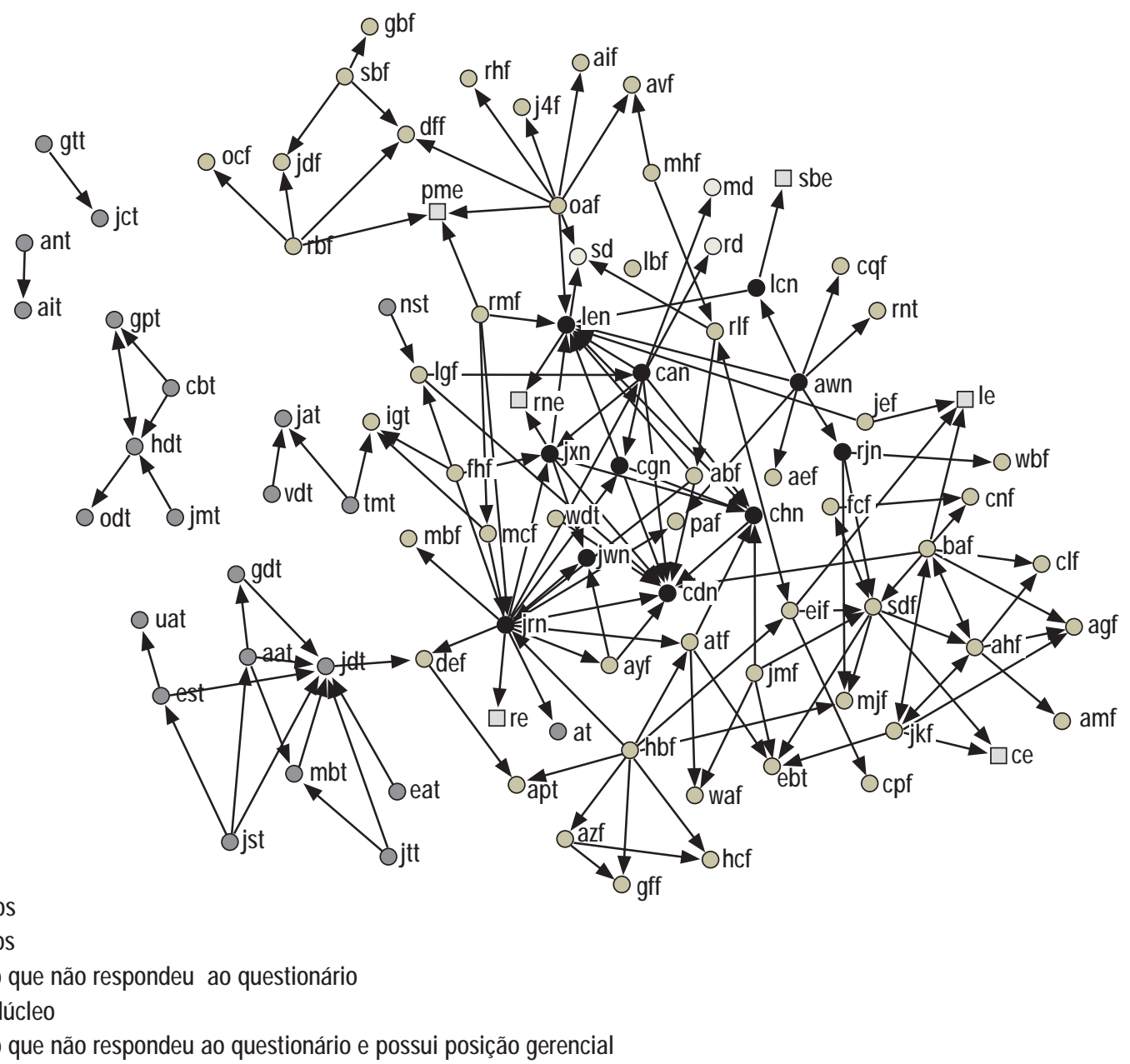


len (positivo), dhn( neutro), jxn( neutro), sdf (neutro), jdt (positivo). Caracterizam-se como expansores de fronteira os atores: def (positivo) e jgf ( não respondeu), por ligarem os terceirizados à rede de informação.

Os atores críticos que fazem parte do subgrupo do núcleo (jrn, len, chn, jxn) evocaram idéias relacionadas à decisão política, gestão administrativa, resultados empresariais, crescimento profissional e expectativas de melhorias. Já soff evocou mudanças na remuneração, pessoas e custo. Por sua vez, jdt apresentou as idéias de crescimento profissional, expectativa de melhoria, perfil do funcionário e incerteza.

Os conectores centrais são fontes de informação ou pessoas na rede com as quais todos se comunicam (Cross e Prusak, 2002). Dentre esses conectores, os que fizeram avaliações neutras da mudança, tais como jrn, sdf e chn, estão cercados por pessoas que fizeram avaliações positivas, negativas e neutras. Ou seja, à primeira vista, não se percebe um compartilhamento na natureza da avaliação realizada. 0 ator jxn destacou-se por realizar uma avaliação neutra, e os demais que estão ligados a ele compartilharam também da mesma percepção. 0 ator len apresentou uma avaliação positiva, não compartilhada com os atores a sua volta. 0 ator jdt compartilhou com todos os atores com os quais se relaciona uma visão positiva sobre a mudança que está em processamento na empresa. Vê-se que um ator importante para a compreensão do compartiIhamento é cdn, que não respondeu ao questionário.
Ao focarmos a atenção nos expansores de fronteira, def ejgf evidenciam os papéis deligação entre o subgrupo dos terceirizados e a rede. Os expansores de fronteira têm um importante papel em situações em que as pessoas precisam partilhar diferentes tipos de habilidades, por exemplo, estabel ecer alianças estratégicas e desenvolver novos produtos (Cross e Prusak, 2002). 0 ator def, apesar de ser funcionário, compartilhou com os terceirizados uma visão positiva. A impossibilidade de acesso à avaliação de jgf, já que ele não respondeu ao questionário, não permite uma análise mais aprofundada do seu papel.

Os resultados analisados não permitem generalizações, não sendo possível determinar se a pouca influência dos atores se deve à natureza da aval iação (positiva, negativa ou neutra) ou à relação em si (baixa coesão ou relações não recíprocas). Assim, os dados não são suficientes para afirmar que a avaliação positiva do ator crítico tenha mais poder de contaminar os indivíduos da rede (afetando 0 grau de compartilhamento) do que a avaliação neutra, por exemplo. De qualquer modo, a avaliação de natureza neutra não parece estar influenciando as avaliações das pessoas que circundam os atores críticos. Essa afirmação não invalida o pressuposto de que os atores críticos possuem potencial para influenciar as avaliações das pessoas com as quais mantêm conexões nas redes. Ressalta-se também que os índices de baixa coesão podem estar influenciando o grau de compartilhamento, uma vez que o cliquemostrou que o subgrupo coeso evidencia alto grau

Figura 3 - Rede de informação simetrizada.
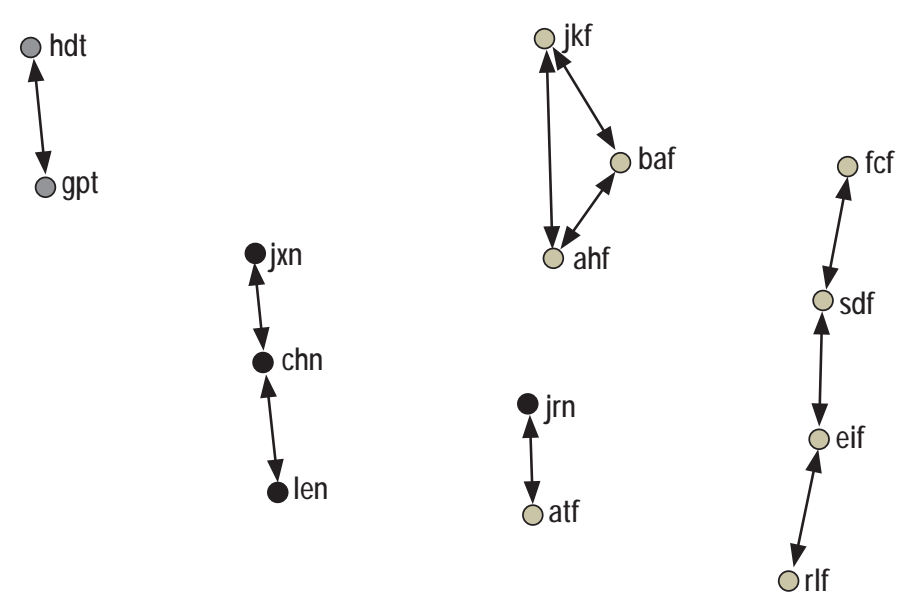

Terceirizados

- Funcionários

- Grupo do Núcleo 
de compartilhamento. De qual quer modo, não podemos perder de vista que al guns atores citados não responderam ao questionário, o que natural mente afeta o resultado em tela.

A avaliação da mudança realizada pelos atores do dique, composto por jkf- ahf- baf, está representada na Figura 5. Os três atores ten deram a evocar idéias mais positivas sobre a mudança (avaliação positiva representada com a cor cinza). Ao analisar os conteúdos evocados por essa tríade de funcionários é possível confirmar o que a literatura teoriza sobre o grau de integração gerado pelos diques.

Embora a avaliação da tríade seja positiva, ao analisar seu conteúdo é possível perceber um posicionamento mais crítico - que é uma tendência desse subgrupo (em comparação com os terceirizados e com o núcleo). Os atores do clique, portanto, evocaram significados que estão em consonância com o seu grupo de referência (grupo dos funcionários). Quando solicitados a opinar sobre a mudança mais importante, os três funcionários se referiram à reestruturação e mudança de donos da empresa, ou seja, à privatização. Quando solicitados a evocar idéias sobre essa mudança, os funcionários se referiram às categorias "Gestão administrativa", "Decisão política", "Redução de quadro", "Sobrecarga de trabalho" e "Expectativa de melhorias".

Esses funcionários do cliqueassociaram a mudança aos aspectos mais específicos e gerenciais, tais como política, gestão e planejamento administrativo, demonstrando reconhecer melhorias - o que representa um conteúdo mais geral e positivo. Por outro lado, idéias negativas associadas à demissão e acréscimo de trabal ho também apareceram. Uma hipótese que poderia ajudar a entender essa aparente contradição é a associação entre demissões e planejamento administrativo, visando à competição no mercado, principalmente no caso de fusões. As demissões são justificadas como estratégia de enxugamento que levaria ao dinamismo da empresa, e essa idéia parece ser captada pel os funcionários.

Embora guiados pelo objetivo de identificar níveis de compartilhamento, os dados apresentados revelam que convergem, no interior da rede, significados distintos

Figura 4 - Percepções sobre a mudança na rede de informação.

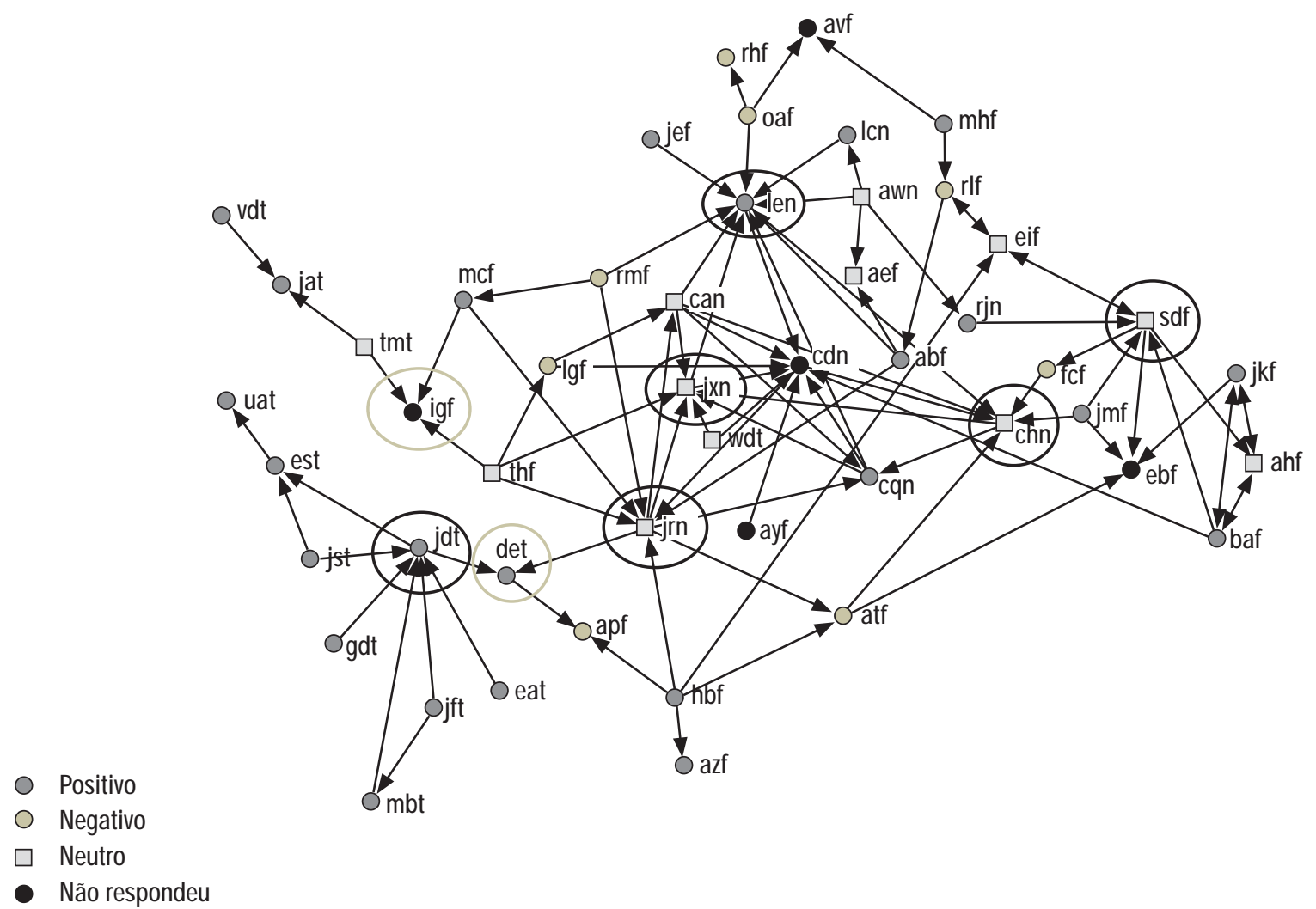


quanto ao processo de privatização da empresa, quer quanto a conteúdo como quanto à dimensão avaliativa. Essa diversidade talvez seja a marca principal de todos os fenômenos psicossociais e aponta claramente as razões pelas quais a gestão dos processos de mudança é sempre al go complexo e desafiador para os gestores.

\section{CONCLUSÕES}

A análise das redes sociais tem se prestado ao exame de uma expressiva gama de fenômenos organizacionais. Da mesma forma, os processos de mudança têm sido alvo de um crescente número de pesquisas, no Brasil e no exterior. A principal contribuição deste artigo é a busca pioneira pela compreensão do compartilhamento do significado da mudança no interior das redes sociais informais. Essa contribuição destaca-se especialmente no plano metodológico, especificamente na exploração da integração de duas estratégias de pesquisa, oriundas de domínios próprios de investigação - cognição e redes sociais. Assim, os resultados obtidos são estimulantes no sentido de tornar a anál ise de rede social mais uma ferramenta para a compreensão das mudanças organizacionais.

0 estudo levantou, neste grupo, uma variedade de informações sobre os significados que podem ser atribuídos às mudanças. 0 mapa cognitivo sobre a mudança organizacional forneceu um panorama geral dos conteúdos evocados pelos respondentes, explicitando tanto idéias mais fortes quanto mais fracas associadas ao processo de mudança. A evocação livre de idéias associadas à mudança permitiu identificar limitações, lacunas e possíveis motivos de resistência envolvidos na criação de significado sobre a mudança em tela.

De modo geral, a privatização foi aval iada positivamente entre os respondentes e está associada, principalmente, à possibilidade de crescimento profissional e pessoal, a melhores resultados e/ou produtividade, e ainda às mudanças na gestão administrativa, planejamento e distribuição do tempo. Considera-se que o predomínio de avaliações positivas é esperado em um grupo de pessoas que sobreviveu ao processo de privatizações e se percebe beneficiado pelas mudanças. Apesar desse predomínio de avaliações positivas, verificamos aquilo que a grande maioria dos estudos tem identificado - as mudanças são, também, fonte de tensão, ansiedade e, portanto, alvo de avaliações negativas.

Os resultados da análise macroestrutural tanto nas redes simetrizada como nas não simetrizadas indicaram as preferências de relacionamento para buscar informações relevantes para o seu trabalho dentro dos subgrupos, verificando-se baixos índices de coesão e de densidade.

Os resultados de alto grau de compartilhamento no cliqueconfirmaram as proposições teóricas que ressal tam a al ta convergência entre cognições, atitudes e comportamentos nos subgru pos coesos. No entanto, fora do exame

Figura 5 - Percepções sobre a mudança no clique a partir dos egos: jkf, ahf, baf.

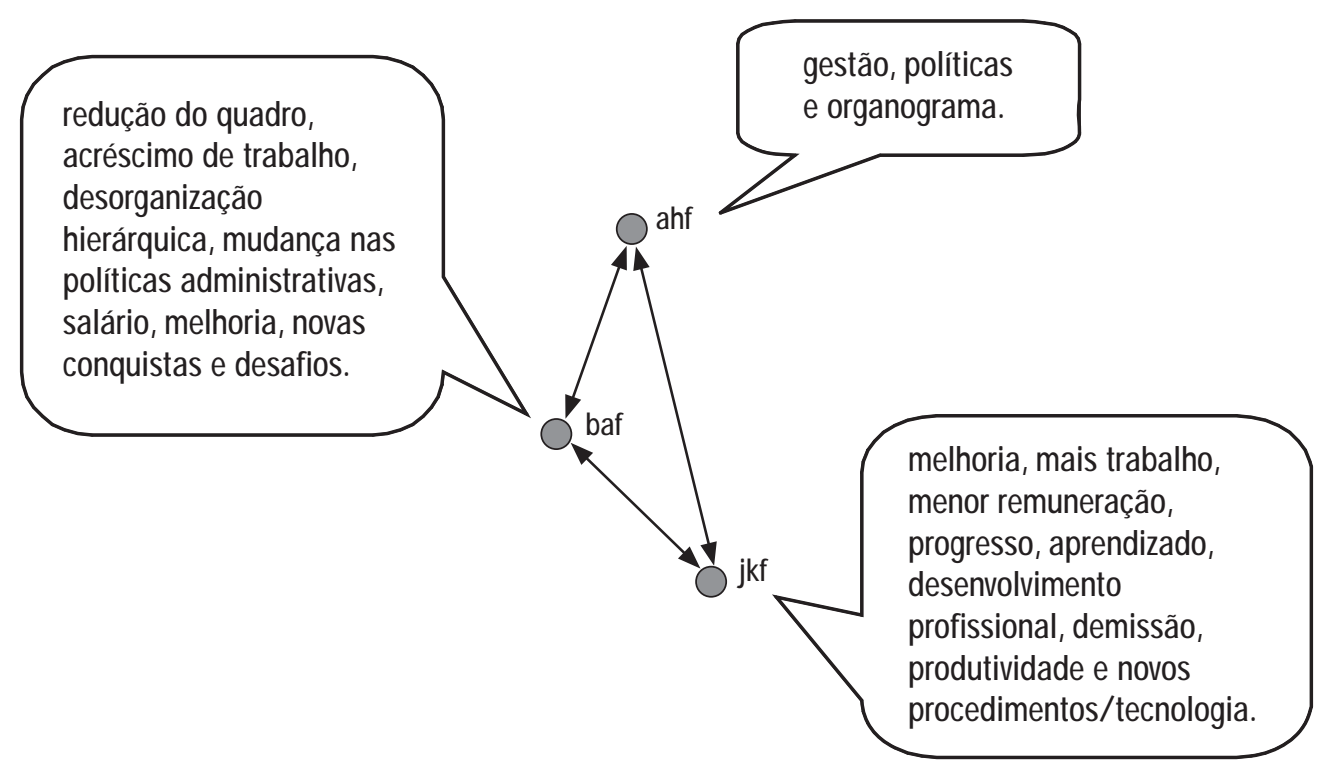


do único diqueexistentena rede, não se percebeu uma clara associação entre a avaliação da mudança entre os atores críticos e a dos atores diretamente ligados a eles naquela rede. Os dados obtidos não são suficientes para determinar se a pouca influência dos atores se deve à natureza da avaliação ou à relação em si (baixa coesão ou relações não recíprocas). Considera-se que os índices de baixa coesão podem estar influenciando o grau de compartilhamento, uma vez que o diquemostrou que o subgrupo coeso evidencia alto grau de compartilhamento.

0 presente trabalho buscou articular o estudo das cognições sobre a mudança com os padrões de interação que configuram as redes sociais informais nas organizações. É importante, assim, tecer al gumas considerações que podem ser relevantes no sentido de sugerir, para estudos futuros, novas possi bilidades de articulação e, sobretudo, o aprimoramento das lacunas existentes no presente trabal ho.

Estudos posteriores poderão utilizar uma escala quantitativa para aval iar as percepções sobre a mudança, o que permitiria, ao longo das possíveis dimensões ou fatores que constituíssem tal escala, fazer-se uma clara associação entre os posicionamentos dos atores envolvidos em cada rede. A distância ou proximidade de julgamentos seria mais facilmente identificada a partir de escores quantitativos do que nas categorias utilizadas, que podem estar descrevendo de forma imprecisa o posicionamento de cada ator (visão positiva, neutra ou negativa da mudança).

Embora não tenha sido o foco deste estudo, o fenômeno da terceirização, e suas conseqüências para os dias atuais, também poderá ser abordado e anal isado segundo a perspectiva das redes sociais informais. Um subproduto não esperado ou intencional mente buscado no estudo emergiu dos resultados eaponta para uma importante e atual questão organizacional - a precária inserção de trabalhadores com vínculos indiretos com a própria empresa, nas redes sociais que envolvem funcionários e gestores.

0 estudo atual evidencia ainda a possibilidade de articulação teórica entre redes sociais e aprendizagem organizacional. Essa relação tem como base o potencial da rede para compartilhamento de significados, informações e conhecimento tácito que é considerado fundamental para a aprendizagem organizacional. Outros fenômenos que podem ser investigados são conflito organizacional e motivação. A fotografia a partir da análise de redes sociais pode ser um ponto de partida para a investigação da dinâmica associada aos estudo da disseminação de informações e compartilhamento de significados e percepções. Para tanto, estudos com recortes Iongitudinais se mostrariam mais completos para apreender a dinâmica envolvida nas relações interpessoais em contexto de trabalho.
Finalmente, vale destacar que os resultados apresentados não esgotam as possibilidades de análise do material coletado. 0 recorte efetuado foi guiado pelo objetivo central de explorar o nível de compartilhamento de significados, e novas análises deverão aprofundar a compreensão da intensidade dos vínculos que ligam os diversos atores, o que permitirá acesso a novas informações sobre o fenômeno investigado.

\section{REFERÊNCIAS}

BASTOS, A. V. B.; SANTOS M. V. O 'schema' de trabalhador comprometido: elemento definidor da identidade no trabal ho [Resumo]. In: REUNIÃO ANUAL DE PSICOLOGIA. SOCIEDADE BRASILEIRA DE PSICOLOGIA, 30., 2000, Brasília. Anais. Brasília: 2000.

BASTOS, A. V. B. Cognição e ação nas organizações. In: DAVEL, E.; VERGARA, S. C. (Orgs.) Gestão com pessoas e subjetividade. São Paulo: Atlas, 2001.

BASTOS, A. V. B.; SOUZA, J. A. J.; COSTA, V. M. F. Explicações e justificativas para a mudança organizacional: mapeando as concepções que guiam executivos centrais. In: ENCONTRO DE ESTUDOS ORGANIZACIONAIS, Anais. Atibaia: 2004.

BORGATTI, S. P.; EVERETT, M. G.; FREEMAN, L. C. Ucinet 6.0 version 1.0. Analytic Technologies, Software for social network analysis. Boston, MA: Harvard, 2002. Disponível em: বhttp://www.analytictech.com/downloaduc6.htm>. Acesso em: jul. 2004.

CALDAS, M. P.; HERNANDEZ, J. M. C. Resistência à mudança: uma revisão crítica. Revista de Administração de Empresas, v. 41, n. 2, p. 31-45, abr./jun. 2001.

CÂNDIDO, G. A.; ABREU, A. F. Os conceitos de redes e as relações interorganizacionais: um estudo exploratório. In: ENCONTRO NACIONAL DA ASSOCIAÇÃO NACIONAL DOS PROGRAMAS DE PÓS-GRADUAÇÃO EM ADMINISTRAÇÃO, 24., 2000, Florianópolis. Anais. Florianópolis: ANPAD, 2000.

CARVALHO, M. R. O. Redes sociais e papel da reputação na formação de alianças estratégicas: 0 caso multiplex Iguatemi. In: ENCONTRO NACIONAL DA ASSOCIAÇÃO NACIONAL DOSPROGRAMASDE PÓSGRADUAÇÃO EM ADMINISTRAÇÃO, 24., 2000, Florianópolis. Anais. Florianópolis: ANPAD, 2000.

CROSS, R.; PRUSAK, L. The people who make organizations go - or stop. Harvard Business Review, v. 80, n. 6, p. 104-112, 2002.

GONÇALVES, S. A.; MACHADO-DA-SI LVA, C. L. Mudança organizacional: institucionalização e cognição na análise do caso da Companhia Paranaense de Energia. In: ENCONTRO NACIONAL DA ASSOCIAÇÃO NACIONAL 
DOS PROGRAMAS DE PÓS-GRADUAÇÃO EM ADMINISTRAÇÃO, 21., 1999, Foz do Iguaçu. Anais. Foz do Iguaçu: AN PAD, 1999.

HASEGAEWA, M.; FURTADO, A. T. Em direção a um modelo de criação e circulação do conhecimento em redes de inovação. In: ENCONTRO NACIONAL DA ASSOCIAÇÃO NACIONAL DOS PROGRAMAS DE PÓS-GRADUAÇÃO EM ADMINISTRAÇÃO, 23., 2001, Campinas. Anais. Campinas: AN PAD, 2001.

KILDUFF, M.; TSAI, W. Social networks and organizations. London: Sage, 2003.

KRACKHARDT, D.; PORTER, L. W. The snowball effect: turnover embedded in communication networks. Journal of Applied Psychology, v. 71, n. 1, p. 50-55, 1986.

KUIPERS, K. J. Formal and informal networks in the workplace. p. 117 (Doutorado em Administração). Stanford, CA: Stanford University, 1999.

LIMA, S. M. V.; BRESSAN , C. L. Mudança organizacional: uma introdução. In: LIMA, S. M. V. (Org.). M udança organizacional: teoria e gestão. Rio de Janeiro: Fundação Getúlio Vargas, 2003.

LOIOLA, E.; MOURA, E. Análise de redes: uma contribuição aos estudos organizacionais. In: FISCHER T. M. (Org.). Gestão contemporânea, cidades estratégicas e organizações locais. $2^{\circledR}$ ed. Rio de Janeiro: Fundação Getúlio Vargas, 1997.

MACHADO-DA-SILVA, C. L.; FERNANDES, B. H. R. Mudança ambiental e reorientação estratégica: estudo de caso em instituição bancária. Revista de Administração de Empresas, v. 38, n. 4, p. 46-56, out./dez. 1998.

MACHADO-DA-SILVA, C. L; FONSECA, V. S.; FERNANDES, B. H. R. Mudança e estratégia nas organizações: perspectiva cognitiva e institucional. In: ENCONTRO NACIONAL DA ASSOCIAÇÃO NACIONAL DOS PROGRAMASDE PÓS-GRADUAÇÃO EM ADMINISTRAÇÃO, 22., 1998, Foz do Iguaçu. Anais. Foz do Iguaçu: AN PAD, 1998.
MINHOTO, L. D.; MARTINS, C. E. As redes e o desenvolvimento social. Cadernos Fundap, n. 22, p. 81-101., 2001.

OLIVER, C. N etwork relations and loss of organizational autonomy. H uman Relations, v. 44, n. 9, p. 943-961, 1991.

PEN NO L. F. L. A empresa em rede sob a ótica das interações. RAE-eletrônica, v. 1, n. 2, jul./dez. 2002.

PODOLNY, J. M; STUART, T. E.; HAN NAN, M. T. Network, knowledge, and niches: competition in the worldwide semiconductor industry, 1984 1991. The American Journal of Sociology, v. 102, n. 3, p. 659-689, 1996.

SCOTT, J. Social N etwork Analysis. London: Sage Publications, 2000.

SILVA, M. C. M. Redes sociais intra-organizacionais informais e gestão: um estudo nas áreas de manutenção e operação da planta Hyco - 8. Dissertação (M estrado em Administração). Salvador: N PGA, Universidade Federal da Bahia, 2003.

SILVA, J. R. G.; VERGARA, S. C. A mudança organizacional pela ótica dos indivíduos: resistência ou uma questão de sentimentos, significado e construção do sujeito? In: ENCONTRO NACIONAL DA ASSOCIAÇÃO NACIONAL DOS PROGRAMAS DE PÓS-GRADUAÇÃO EM ADMINISTRAÇÃO, 24., 2002, Recife. Anais. Recife: AN PAD, 2002.

WASSERMAN, S.; FAUST, K. Social Network Analysis - Methods and Applications. Cambridge: Cambridge University Press, 1998.

WEICK, K. E. Perspectives on action in organizations. In: LORSCH, J. W. (Org.). Handbook of Organizational Behavior. Englewood Cliffs, NJ: Prentice-Hall, 1987. p. 10-28.

WOOD JR.; T. Mudança organizacional: introdução ao tema. In: WOOD JR., T. (Org). M udança organizacional: aprofundando temas atuais em administração de empresas. 2a ed. São Paulo: Atlas, 2000. Cap. 1, p. 17-33.

\section{Artigo recebido em 22.11.2004. A provado em 05.01.2007.}

\section{Antonio Virgílio B. Bastos}

Professor do mestrado em Psicologia na UFBA

Interesses de pesquisa nas áreas de comprometimento, redes sociais e cognição social.

E-mail: antoniovvirgilio@uol.com.br

Endereço: Rua M acapá, 461, apto. 601, Salvador - BA, 40170-150.

\section{Mariana Viana Santos}

Mestre em Psicologia pela UFBA

Interesses de pesquisa nas áreas de redes sociais, competências e cognição social.

E-mail: mariana.viana@uol.com.br

Endereço: Av. Magal hães N eto, 753, apto. 312, Salvador - BA, 41820-011. 